public by the news media. The random sampling of America's newspapers suggests that we have a long way to go. Ongoing tracking of these inaccuracies may offer one measure of how our profession's advocacy and education affects the media and succeeds at reducing stigma toward our patients.

\section{Acknowledgment}

This work was supported by a grant from the National Alliance for the Mentally Ill.

\section{References}

1. Warner R: Combating the stigma of schizophrenia. Epidemiologia e Psichiatria Sociale 10:12-17, 2001
2. Link BG, Cullen FT, Frank J, et al: The social rejection of former mental patients: understanding why labels matter. American Journal of Sociology 92:1461-1500, 1987

3. Perlick DA, Rosenheck RA, Clarkin JF, et al: Stigma as a barrier to recovery: adverse effects of perceived stigma on social adaptation of persons diagnosed with bipolar affective disorder. Psychiatric Services 52: $1627-1632,2001$

4. Sontag S: Illness as Metaphor. New York, Farrar, Straus and Giroux, 1978

5. Clow B: Who's afraid of Susan Sontag? or, the myths and metaphors of cancer reconsidered. Social History of Medicine 14: 293-312, 2001

6. Bleuler $\mathbf{E}$ : The prognosis of dementia praecox: the group of schizophrenias, in The Clinical Roots of the Schizophrenia Concept: Translations of Seminal European Contributions on Schizophrenia. Edited by
Cutting J, Shepherd M. New York, Cambridge University Press, 1987

7. Philo G, Secker J, Platt S, et al: The impact of the mass media on public images of mental illness: media content and audience belief. Health Education Journal 53:271-281, 1994

8. Shain RE, Phillips J: The stigma of menta illness: labeling and stereotyping in the news, in Risky Business: Communicating Issues of Science Risk and Public Policy Westport, Conn, Greenwood, 1991

9. Wilson C, Nairn R, Coverdale J: How mental illness is portrayed in children's television: a prospective study, British Journal of Psychiatry 176:440-443, 2000

10. Link BG, Struening EL, Rahav M, et al: On stigma and its consequences: evidence from a longitudinal study of men with dual diagnoses of mental illness and substance abuse. Journal of Health and Social Behavior 38:177-190, 1997

\title{
Awareness and Perceptions of a Communitywide Mental Health Program in New York City After September 11
}

\section{Sasha Rudenstine}

Sandro Galea, M.D., M.P.H.

Jennifer Ahern, M.P.H.

Chip Felton, M.S.W.

David Vlahov, Ph.D.

The Project Liberty program was established after the terrorist attacks of September 11, 2001, to offer free mental health services to New York City residents. The authors used data from a random-

Ms. Rudenstine, Dr. Galea, Ms. Ahern, and Dr. Vlahov are affiliated with the Center for Epidemiologic Studies of the New York Academy of Medicine in New York City. Mr. Felton is with the New York State Office of Mental Health in Albany. Send correspondence to Dr. Galea at 1216 Fifth Avenue, New York, New York 10029 (e-mail,sgalea@nyam.org). digit-dial telephone survey to assess public awareness of and willingness to make use of Project Liberty's services. They found that 24 percent of the New York City residents surveyed (480 of 2,001 respondents) had heard of Project Liberty four months after September 11. Persons with lower socioeconomic status and those who had psychological symptoms consistent with posttraumatic stress disorder were more likely to say that they would contact Project Liberty. The results of the study suggest that al- though awareness of this public mental health services was low, Project Liberty was well received among the people who may be most likely to need its services. (Psychiatric Services 54:14041406, 2003)

Droject Liberty was established by P the New York State Office of Mental Health in response to the terrorist attacks of September 11, 2001 , to provide free educational and crisis counseling services to residents of the New York City metropolitan area. The program, which is still in operati categories of persons whe symptoms of such as postt! (PTSD) and reach to th through edu able counsel

Project L widely adv such as tel boards thre City area 2001. Detai program ha where (1). awareness program hi for the pro ly for simi ter urban c

We asse and willin ject Libert survey of several mo tacks. We the level o erty, the who were or to say Project L with psy more or and to us

Methods A randor (in Engli City hou ing Janu the pros for thre mentati $2002, \mathrm{P}$ than 42 cluding group ing ser sons (1 survey least 1 New Y overall vey wi cluded dents' exposı 11 , an PSYCHL: 
still in operation, provides two broad categories of services: services for persons who have demonstrated symptoms of psychological illnesses, such as posttraumatic stress disorder (PTSD) and depression, and outreach to the general population through education and widely available counseling services.

Project Liberty's services were widely advertised through media such as television, radio, and billboards throughout the New York City area starting in November 2001. Details of the Project Liberty program have been published elsewhere (1). Understanding public awareness and acceptance of this program has important implications for the program itself and potentially for similar programs initiated after urban disasters.

We assessed public awareness of and willingness to make use of Project Liberty's services by conducting a survey of New York City residents several months after the terrorist attacks. We were interested in assessing the level of awareness of Project Liberty, the characteristics of persons who were more likely to have heard of or to say that they would telephone Project Liberty, and whether persons with psychological symptoms were more or less likely to have heard of and to use Project Liberty.

\section{Methods}

A random-digit-dial telephone survey (in English and Spanish) of New York City households was conducted during January and February 2002, when the program had been in operation for three months. From the implementation of the program to March 2002, Project Liberty provided more than 42,000 service encounters, including individual counseling and group education sessions, representing services to more than 91,000 persons (1). The sampling frame for this survey was adults (persons aged at least 18 years) who were living in New York City on September 11. The overall cooperation rate for the survey was 64 percent. The survey included questions about the respondents' demographic characteristics, exposure to the events of September 11 , and psychological symptoms since

\section{Table 1}

Bivariate relations between characteristics of study participants and awareness, impressions, and likelihood of telephoning Project Liberty four or five months after the September 11 terrorist attacks (total $\mathrm{N}=2,001)^{\text {a }}$

\begin{tabular}{|c|c|c|c|c|c|c|}
\hline \multirow[b]{2}{*}{ Variable } & \multicolumn{3}{|c|}{$\begin{array}{l}\text { Heard of Project } \\
\text { Liberty }(\mathrm{N}=480 \text {, or } 24 \%)\end{array}$} & \multicolumn{3}{|c|}{$\begin{array}{l}\text { Likely to call Project } \\
\text { Liberty }(\mathrm{N}=92 \text {, or } 23 \%)\end{array}$} \\
\hline & $\mathrm{N}$ & $\%$ & $\mathrm{p}^{\mathrm{b}}$ & $\mathrm{N}$ & $\%$ & $\mathrm{p}^{\mathrm{c}}$ \\
\hline Age & & & .03 & & & .4 \\
\hline Younger than 45 years & 262 & 22 & & 50 & 21 & \\
\hline 45 years or older & 208 & 27 & & 41 & 25 & \\
\hline Gender & & & .3 & & & .62 \\
\hline Male & 210 & 23 & & 43 & 24 & \\
\hline Female & 270 & 25 & & 49 & 21 & \\
\hline Race & & & .13 & & & $<.001$ \\
\hline White & 244 & 28 & & 18 & 9 & \\
\hline Asian & 16 & 17 & & 3 & 23 & \\
\hline African American & 105 & 22 & & 33 & 32 & \\
\hline Hispanic & 94 & 22 & & 34 & 40 & \\
\hline Other & 15 & 23 & & 4 & 26 & \\
\hline Annual income & & & .03 & & & .003 \\
\hline Less than $\$ 20,000$ & 63 & 17 & & 22 & 42 & \\
\hline$\$ 20,000$ to $\$ 29,999$ & 60 & 28 & & 16 & 31 & \\
\hline$\$ 30,000$ to $\$ 39,999$ & 55 & 22 & & 10 & 22 & \\
\hline$\$ 40,000$ to $\$ 49,999$ & 46 & 26 & & 10 & 22 & \\
\hline$\$ 50,000$ to $\$ 74,999$ & 62 & 24 & & 10 & 19 & \\
\hline$\$ 75,000$ to $\$ 99,999$ & 47 & 34 & & 4 & 12 & \\
\hline$\$ 100,000$ or more & 63 & 26 & & 4 & 7 & \\
\hline Education & & & $<.001$ & & & .01 \\
\hline Less than high school & 31 & 17 & & 17 & 63 & \\
\hline High school or equivalent & 86 & 19 & & 17 & 23 & \\
\hline Some college & 128 & 29 & & 26 & 19 & \\
\hline Finished college & 150 & 25 & & 23 & 19 & \\
\hline Some graduate work & 84 & 31 & & 8 & 13 & \\
\hline Internet access & & & $<.001$ & & & .007 \\
\hline Yes & 361 & 27 & & 58 & 18 & \\
\hline No & 117 & 17 & & 33 & 35 & \\
\hline Immigrant to the United States & & & $<.001$ & & & $<.001$ \\
\hline Yes & 129 & 19 & & 46 & 41 & \\
\hline No & 350 & 27 & & 46 & 14 & \\
\hline Current health insurance & & & .01 & & & .02 \\
\hline No & 73 & 19 & & 22 & 37 & \\
\hline Yes & 406 & 25 & & 70 & 20 & \\
\hline Current probable PTSD & & & .77 & & & .007 \\
\hline Yes & 33 & 23 & & 16 & 54 & \\
\hline No & 447 & 24 & & 76 & 20 & \\
\hline
\end{tabular}

a The numbers represent the numbers of respondents; the percentages are weighted to reflect oversampling, number of persons in the household, and number of telephones in the household.

b For comparison of positive impression of Project Liberty with neutral or negative impression; two tailed chi square test

c For comparison of persons who said they would definitely or probably telephone Project Liberty with persons who said they would definitely not call or probably not call Project Liberty; twotailed, chi square test

September 11. Further details about the survey and measures used have been published $(2-5)$.

We asked respondents whether they had heard of Project Liberty. Persons who had heard of Project Liberty were asked for their impressions of the program and how likely it was that they would make use of Project Liberty's services in future.
We calculated the prevalence of awareness of Project Liberty. We assessed the bivariate relations between the covariates of interest and awareness of and likelihood of telephoning Project Liberty. We also assessed the relations between persons who met criteria for probable PTSD and their awareness of and likelihood of telephoning Project Liberty. 


\section{Results}

The sample comprised 2,001 adults. The demographic breakdown of our sample was comparable to that of the 2000 U.S. Census for the same sampling area (6). Overall, 24 percent of persons interviewed $(\mathrm{N}=480)$ were aware of Project Liberty. Among respondents who had heard of Project Liberty, 273 (67 percent) had a good impression of the program, and 92 (23 percent) thought that they would telephone the hotline to request services.

Variables that were significantly associated with having heard of Project Liberty were being older, having a higher income, having more education, having Internet access, being a U.S. citizen, and having current health insurance, as can be seen from Table 1. Variables that were significantly associated with respondents' reporting that they would be likely to telephone Project Liberty were belonging to a racial minority, having a low income, having less education, not having Internet access, being an immigrant to the United States, having no current health insurance, and having symptoms consistent with current probable PTSD.

\section{Discussion and conclusions}

Recent research has shown that the mental health consequences of a large human-made disaster in a densely populated urban area can be substantial $(2,7)$. Although a number of approaches have been adopted in the past to provide mental health services to persons affected by various disasters, few formal evaluations of these programs have been published.

Our study showed that despite considerable attempts to inform the public of Project Liberty, only 24 percent of New York City residents had heard of the program four months after September 11. This finding suggests that it is difficult to publicize a program intended to provide counseling services, even when public awareness of issues related to a particular disaster are very high. Encouragingly, among persons who were aware of Project Liberty, perception of the program was largely positive, and persons who reported that they would be likely to telephone Project Liberty had a higher prevalence of mental health symptoms. Persons with indicators of higher socioeconomic status were more likely to have heard of Project Liberty. This finding may reflect greater access within this group to the mass media and other resources. The association between awareness of Project Liberty and Internet access supports this hypothesis. However, we found that persons of lower socioeconomic status said that they were more likely to make use of Project Liberty services.

In conjunction with our earlier observation that persons of lower socioeconomic status may be more likely to experience psychological consequences after a disaster (4), this finding has two implications. First, Project Liberty may be meeting a need that would otherwise have remained unmet in making mental health services available to persons with lower incomes. Second, greater effort to increase awareness of Project Liberty among socioeconomically disadvantaged groups may be warranted. For example, the lower awareness of Project Liberty among immigrant groups combined with the higher willingness of these groups to use the program suggests that immigrant groups might benefit from targeted marketing of Project Liberty or similar programs after disasters. We also found that persons with symptoms consistent with probable PTSD were more likely to say that they would telephone Project Liberty, which suggests that the program may reach persons who are likely to benefit from its services.

Our study had a number of limitations. Since the time of this study, public awareness of Project Liberty may have grown and public perceptions of the program may have evolved. Follow-up work will be necessary to investigate evolving awareness and perceptions of Project Liberty. We asked respondents only about whether they were likely to use Project Liberty's services; we have no data on respondents' subsequent use of these services. Also, although we explicitly outlined the services provided by Project Liberty, it is possible that some respondents were aware of or planned to use services that were part of Project Liberty without recognizing that these services were in fact
Project Liberty services.

In conclusion, our study showed that awareness of available mental health services was low despite considerable attempts to raise awareness of these services. However, we also found that persons who were more likely to say that they would telephone Project Liberty were those who may have had the greatest need for mental health services after the September 11 disaster. Although a formal evaluation of the efficacy of Project Liberty's services is yet to be conducted, early reports suggest that Project Liberty's services are being used by a broad range of residents of the New York City metropolitan area (8). The results of this study suggest that Project Liberty, although well received by New York City residents, needs to increase its efforts at marketing, particularly to socioeconomically disadvantaged groups.

\section{References}

1. Felton C: Project Liberty: a public health response to the mental health needs of New Yorkers arising from the World Trade Center terrorist attacks. Journal of Urban Health 79:429-433, 2002

2. Galea S, Ahern J, Resnick H, et al: Psychological sequelae of the September 11 terrorist attacks in New York City. New England Journal of Medicine 346:982-987, 2002

3. Galea S, Boscarino J, Resnick $\mathrm{H}$, et al Mental health in New York City after the September 11 terrorist attacks: results from two population surveys, in Mental Health, United States, 2001. Edited by Manderscheid RW, Henderson MJ. Washington DC, US Government Printing Office, 2002

4. Galea S, Resnick H, Ahern J, et al: Posttraumatic stress disorder in Manhattan, New York City, after the September 11th terrorist attacks. Journal of Urban Health $79: 340-353,2002$

5. Vlahov D, Galea S, Resnick H, et al: Increased use of cigarettes, alcohol, and marijuana among Manhattan, New York, residents after the September 11 terrorist attacks. American Journal of Epidemiology 155:988-996, 2002

6. US Census Bureau: Summary tape, file $3 A$ (STF3A). Washington, DC, US Department of Commerce, 1990. Available at www. census.gov

7. Schlenger W, Caddell J, Ebert L, et al: Psychological reactions to terrorist attacks. JAMA 288:581-588, 2002

8. Wunsch-Hitzig R, Plapinger J, Draper J, et al: Calls for help after September 11: a community mental health hot line. Journal of Urban Health 79:417-428, 2002
The stud ferences clinical, a use varia schizoph health $c$ 1999 to tients $w$ were old married surance diagnosi men. Mo depende resided or were significa

Dr. Linda Dr. Hough the depart versity of damer is a vice Netwi Hawthorn Research Dr. Hougl sociology Dr. Folson partment cine of the la; Dr. Fol Diego. D, County $M$ spondenct Diego He Jolla Villa 92161 (e- 